\title{
A Proposed Selection Process in Over-The-Top Project Portfolio Management
}

\author{
Jemy Vestius Confido $^{1}(\mathbb{D})$, Dermawan Wibisono ${ }^{1,2}$ iD , Yos Sunitiyoso $^{1}$ \\ ${ }^{1}$ Institut Teknologi Bandung (Indonesia) \\ ${ }^{2}$ Universitas Pertamina (Indonesia) \\ jemy.confido@sbm-itb.ac.id,dwibisono@sbm-itb.ac.id,yos.sunitiyos@@sbm-itb.ac.id
}

Received: September 2017

Accepted: March 2018

\section{Abstract:}

Purpose: The purpose of this paper is to propose an over-the-top (OTT) initiative selection process for communication service providers (CSPs) entering an OTT business.

Design/methodology/approach: To achieve this objective, a literature review was conducted to comprehend the past and current practices of the project (or initiative) selection process as mainly suggested in project portfolio management (PPM). This literature was compared with specific situations and the needs of CSPs when constructing an OTT portfolio. Based on the contrast between the conventional project selection process and specific OTT characteristics, a different selection process is developed and tested using group model-building (GMB), which involved an in-depth interview, a questionnaire and a focus group discussion (FGD).

Findings: The paper recommends five distinct steps for CSPs to construct an OTT initiative portfolio: candidate list of OTT initiatives, interdependency diagram, evaluation of all interdependent OTT initiatives, evaluation of all non-interdependent OTT initiatives and optimal portfolio of OTT initiatives.

Research limitations/implications: The research is empirical, and various OTT services are implemented; the conclusion is derived only from one CSP, which operates as a group. Generalization of this approach will require further empirical tests on different CSPs, OTT players or any firms performing portfolio selection with a degree of interdependency among the projects.

Practical implications: Having considered interdependency, the proposed OTT initiative selection steps can be further implemented by portfolio managers for more effective OTT initiative portfolio construction.

Originality/value: While the previous literature and common practices suggest ensuring the benefits (mainly financial) of individual projects, this research accords higher priority to the success of the overall OTT initiative portfolio and recommends that an evaluation of the overall portfolio should occur prior to individual evaluation. Consequently, certain initiatives may not provide direct individual benefits. Those initiatives should remain within the portfolio because they are needed for the success of other initiatives.

Keywords: communication service provider (CSP), over-the-top (OTT) initiative, project portfolio management (PPM), interdependency 


\section{Introduction}

The presence of over-the-top (OT'T) services in various forms of digital applications and contents, such as video and music streaming, online games, messaging services, video calls and others, have created new challenges for communication service providers (CSPs), which are also known as telecommunication operators, that have been providing internet and phone connectivity. The challenges can be perceived as direct or indirect threats and opportunities. For many decades, CSPs have possessed a competitive advantage in the network infrastructure that covers wide areas. However, regarding the OTT business, CSPs are having difficulty taking advantage of their own network infrastructure. CSPs should consider providing their own OTT services; however, unfortunately, an OTT business requires addressing different capabilities. Conversely, OT'T players can easily utilize the network provided by CSPs at relatively low overhead costs.

Given the challenge to embrace the OTT business, CSPs must systematically consider their limitations. Among those limitations are the mindset and skills of their employees who need to be shifted from that of an ordinary communication service business to that of a digital OTT business. The business model also becomes an issue for CSPs, since they are used to deploy a one-sided value chain model (Zhao, 2011) in which they act as buyers from the network equipment manufacturers and use various distribution channels to offer their services. However, in the OTT business, other types of business models such as the two-sided markets model (Zhao, 2011; Armstrong, 2006; Rysman, 2009), freemium (Martin, 2012; Needleman \& Loten, 2012) and market capitalization (Morgan Stanley, 2014; Gupta \& Mela, 2008) have been explored to create new profitability. CSPs are also perceived as having a slow time to market in which product development can take years; this continues to be considered normal, while OTT players can deploy their services in months. The business foot print is also an issue for CSPs. Historically, CSPs operated within certain geographical boundaries, while OTT players that operate over the internet could not be geographically limited globally. Many OTT services also involve interdependency and externality, which require special approaches.

Given the above situations, this research raises the following questions for a CSP entering OTT businesses:

1. Should a CSP deploy a conventional portfolio selection process or should it use a different approach?

2. Does the financial aspect remain the primary consideration in the OTT initiative selection process?

3. How can a CSP address the unique characteristics of an OTT business such as interdependency?

There are four aspects in project management that are very relevant to the manner in which CSPs should translate their OTT business strategy into an OTT portfolio: project portfolio management (PPM), strategic orientation, interdependency and resource limitation. The PPM process will ensure the alignment between the business strategy and the project portfolio by cascading business strategy into opportunities and threats, which will then be translated into projects (Morris \& Jamieson, 2004; Turner, 1999). The strategic orientation is meant to align the resource allocation and the project selection with the firm's strategy. Interdependency could partially or entirely determine whether or not an OTT project can be begun before another is completed (Bathallath, Smedberg \& Kjellin, 2016). Eventually, the resource limitation will determine how many OTT projects can be included given the available resources.

\subsection{Project Portfolio Management}

PPM performs evaluation, prioritization and selection of projects, or initiatives, that best meet the objectives of a firm. To perform its function, PPM adopts various tools and methods per individual project evaluation with the objective of selecting projects to be included in the portfolio such that they balance and align with the strategies, resources and vision; this, in turn, will realize benefits and obtain the best results (Cooper, Edgett \& Kleinschmidt, 2001; Levine, 2005). The selection of an individual project is performed using a set of criteria on which each project is scored. Identified potential projects are then analyzed to determine their feasibility (Kerzner, 2009; Martinsuo \& Lehtonen, 2007; Moore, 2010). Gray and Larson (2011) explain that there are five criteria to ensure a well-fitting implementation of a project portfolio system: linkage between project selection and strategic metrics, prioritization of project proposals in accordance with a set of criteria, alignment of resource allocation and strategic direction, risk balancing across all projects and justification to terminate unsupported projects. Both PPM 
studies and practices have a primary focus on how to ensure each individual project will satisfy performance standards before further inclusion into a portfolio. This perspective may potentially disqualify certain projects, although they are needed for the success of other projects.

There are two major components of project selection in PPM. The first component is project ranking; the second is portfolio balancing in which, firms would typically decide to terminate a project either due to its performance or in favor of another project (Archer \& Ghasemzadeh, 2004; Pennypacker \& Retna, 2009; Project Management Institute, 2008). The contribution toward an organization's strategic objectives is very important in the project selection (Gray \& Larson, 2011). Nevertheless, the focus is primarily on individual project selection and tends to neglect the possibility of combining several projects, which may result in different portfolio decisions. Similarly, in highly quantitative $R \& D$ projects, different approaches to the prioritizing system using Balanced Scorecard have been proposed by Stewart (2001) and later extended by Eilat, Golany and Shtub (2008), who identify the means of translating certain aspects of Balanced Scorecard into quantitative measures and then integrate it into a data analysis framework. The use of Balanced Scorecard will ensure project linkage to the strategy; however, it continues to separately consider every project as a single individual project. Project and portfolio management are inter-related in the selection decision process. Business decision makers must choose projects that will optimize the entire portfolio. The underlying question is which activity should be performed first: the evaluation of each project's feasibility or the construction of the overall portfolio?

In common project selection, many practitioners tend to omit unfeasible projects from inclusion in the overall portfolio; thus, they will first conduct an individual project evaluation. Archer and Ghasemzadeh (1999) are the proponents of this approach and have been referred to by many other studies such as Murray, Alpaugh, Burgher, Flachsbart and Elrod (2010), Wheeler (2013), Project Management Institute (2008) and Yu, Wang and Guo. (2008). Archer and Ghasemzadeh (1999) suggest that the portfolio evaluation process consists of two steps that essentially determine the relative worth of each proposed project and that consider all constraints such as project interaction and resource limitations. Archer and Ghasemzadeh (1999) have considered all constraints, including interdependency; however, they recommend the analysis of individual projects should be performed before the selection of the optimal portfolio. Archer and Ghasemzadeh (1999) require that each selected project must match a firm's strategic focus, have sufficient information to make a logical decision and must meet a marginal requirement to be included in the portfolio selection. The researchers propose a framework for project portfolio selection as depicted in Figure 1. In this framework, after projects are selected, they will be included in the optimal portfolio selection. Performance information from the project execution is then fed into the portfolio management process (Archer \& Ghasemzadeh, 1999; Project Management Institute, 2008).

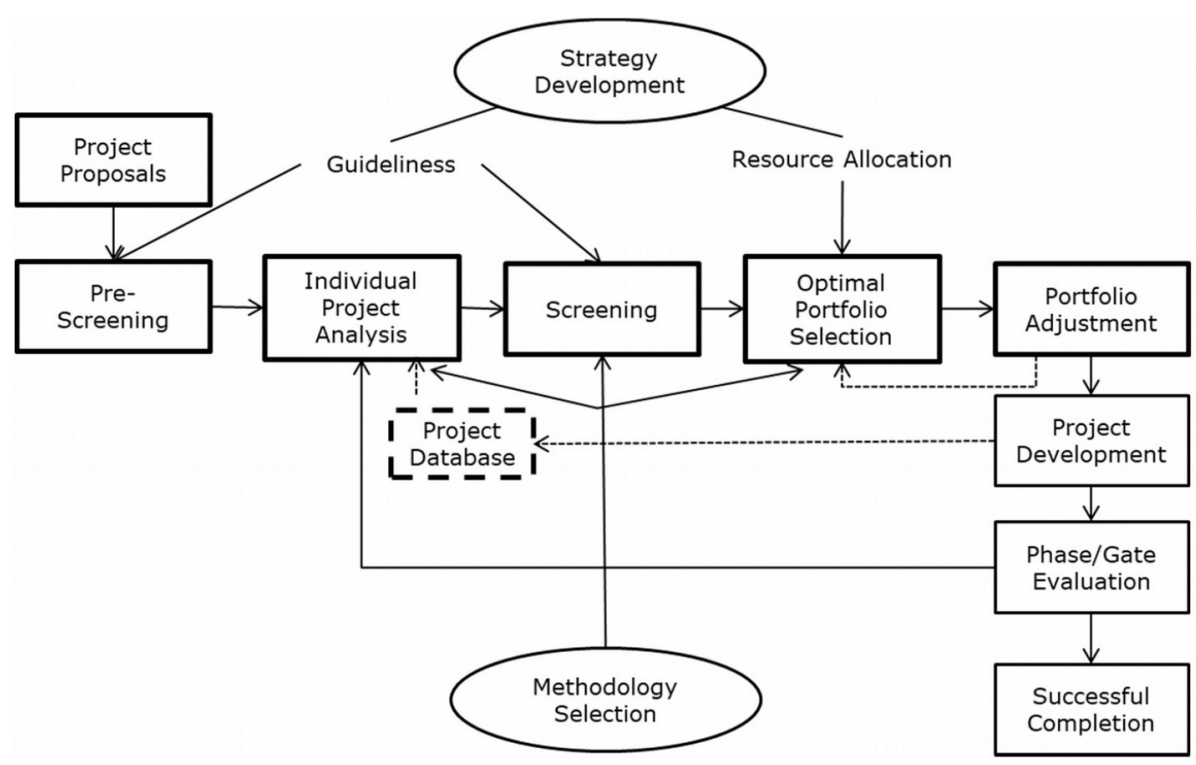

Figure 1. Framework for Project Portfolio Management (Archer \& Ghasemzadeh, 1999) 
Archer and Ghasemzadeh (1999) suggest that, prior to selecting any individual project, a firm must set strategy development guidelines to ensure the alignment between resource allocation and strategic focus. However, in many instances, direct financial impacts, such as Return on Investment (ROI), Return on Average Investment (RAI), Pay Back Period (PBP), Net Present Value (NPV), Internal Rate of Return (IRR), Expected Value (EV) and Economic Value Added (EVA), have become primary considerations of firms' strategy development and focus. In the situation where projects are influencing each other, aligning resource allocation and strategy focus merely based on financial considerations may not be sufficient because certain projects needed for the success of others may be disqualified due to financial considerations.

\subsection{Strategic Orientation}

Strategic orientation is very important (Jiang \& Klein, 1999) to ensure the alignment between resource allocation and project selection in accordance with the firm's strategy. For an effective strategic alignment, a firm is required to utilize an integrated approach, including quantitative and qualitative methods (Kester, Hultink \& Lautche, 2009) and sufficient requirement analysis (Bergman \& Mark, 2002). Muray, Burgher and Alpaugh (2009) address the importance of strategic alignment and pre-defined needs. Appropriate requirements will prevent the firm from selecting unnecessary projects and avoid a project catastrophe, which will be very expensive to recover from. Muller, Martinsuo and Blomquist (2008) empirically prove that alignment of project selection and prioritization must be practiced at organization level. Since interests of the whole organization are to be prioritized over individual needs, alignment between organization's strategy and project selection should be extended to position overall project portfolio construction prior to individual project analysis. This statement is at least feasible in the OTT business, where many projects may converge on the same technology.

Turner (2009) proposes two major criteria: benefit and risk in the effort to establish a linkage between project selection and organizational benefits. However, other criteria may also be included such as strategic importance, stakeholder acceptance and opportunity for learning. This flexibility to include other criteria opens possibility to include financially non-feasible projects; however, it has not considered project interdependency as a whole. Although certain authors suggest non-financial related criteria, project portfolio selection remains dominated by financial and financially related criteria such as risk as suggested by many authors (Lawson, Longhurst \& Ivey, 2006; Jafarizadeh \& Khorshid-Doust, 2008; Murray, Burgher \& Alpaugh, 2009). With strong direct financial impact in consideration, very likely project portfolio managers will evaluate project on individual basis and will disregard interdependency, which could determine overall portfolio success, particularly when relationships among projects are very intensive, as in the OT'T business.

\subsection{Interdependency}

PPM has recognized that project interdependency does exist and should be considered in portfolio construction (Soderlund, 2004; Stummer \& Heidenberger, 2003). The types of interdependency commonly referenced are related to resource allocation, time availability, project sequence (Archer \& Ghasemzadeh, 1999), key people who work simultaneously in many projects (De Maio, Verganti \& Corso, 1994) and competency of the organization and individual (Gutjahr, Katzensteiner, Reiter, Stummer \& Denk, 2008), which can be categorized as resource interdependency. Bathallath et al. Kjellin (2016) explain that resource interdependency occurs when certain resources need to be shared among several projects, particularly if the shared resources are very rare. Consequently, certain projects cannot be started unless another project has completed using those particular resources. However, in the OT'T business case, another type of interdependency, which is called technical interdependency, more commonly occurs. Technical interdependency is the reason that a success of one initiative may affect the probability of success or failure of another initiative (Bathallath et al., 2016). In managing OTT initiatives, technical interdependency is far more likely to occur than other types of interdependencies. Because of its relevance, unless otherwise specified, the term interdependency discussed in this paper refers to technical interdependency.

Multiple project interdependencies are common characteristics of complex project portfolios. However, supported by facts and arguments, Elonen and Artto (2003) argue that management of interdependences is one area of weakness for PPM. PPM has not been able to lead project portfolio managers to the same understanding about definition and influence of project interdependency or how to address it. Although many PPM tools and methods 
provide a portfolio-level perspective (Killen \& Kjaer, 2012), common PPM practices continue to treat each project in isolation as if interdependency does not exist or has no impact on balancing project decisions. This situation could also be partially driven by the fact that effects of interdependency in project portfolio construction are very complex and difficult to analyze (Aritua, Smith \& Bower, 2009). Complexity and difficulty of managing interdependent projects are in parallel with the multi-dimensional challenge, which contains uncertainty and dynamism (Collyer \& Warren, 2009; Perminova, Gustafsson \& Wikstrom, 2008). This challenging field has increasingly attracted more researchers to study project interdependency (Collyer \& Warren, 2009; Elonen \& Artto, 2003; Soderlund, 2004; Stummer \& Heidenberger, 2003), including the project environment, which involves incomplete cost information in the presence of multiple evaluation criteria (Liesio, Mild \& Salo, 2007, 2008). Given the importance, complexity and difficulty of project selection, further PPM practices are largely expected to provide a simple quantitative approach involving non-financial criteria and needs identification in alignment with an organization's strategy; these practices include those studied by Murray et al. (2009) and the OT'T initiative selection process proposed in this paper.

The dynamic environments of project portfolio management always create challenges for better methods and tools (Killen \& Hunt, 2010), including those that are related to project interdependency. Analytical tools such as network mapping could enhance the understanding of project portfolio managers of interdependency. Graphical and visual methods investigated by Killen and Kjaer (2012) are believed to strengthen the handling of project interdependency in the PPM processes. A very common graphical and visual method to enhance understanding of project interdependencies is two-dimensional dependency matrices (Dickinson, Thornton \& Graves, 2001, Slade, 2009), which function by capturing inward and outward between interdependent projects. Nevertheless, Killen and Kjaer (2012) state that the two-dimensional approach remains insufficient to highlight cumulative dependencies in a project portfolio; therefore, more complex visualization methods using two-and-a-half dimensional displays are recommended (Warglien, 2010). To achieve simple and easy-to-use methodologies and tools, discussion of this research will be limited to two-dimensional displays.

Understanding project interdependencies is very essential for effective project selection (Blau, Pekny, Varma \& Bunch, 2004; Verma \& Sinha, 2002). Effective or ineffective management of these interdependencies will, in turn, contribute to the portfolio success or failure. To address issues pertaining to interdependent projects and then leverage related benefits, firms deploy hard practices and soft practices (Tasevska, Toropova \& Vanyushyn, 2013). Hard practices make it possible for a firm to identify project interdependencies; however, they do not provide managerial solutions. A more prevailing mechanism is found in the soft practices. Tasevska et al. (2013) argue that a combination of both hard and soft practices could be very potent for effective project interdependency management. One means to exercise both hard and soft practices is deploying a procedure to consider interdependency prior to portfolio construction. This procedure will be further examined in this research.

The behavior of an organization and its people also play important role in the adoption of project interdependency into project selection and portfolio construction (Blau et al., 2004; Verma \& Sinha, 2002). Discipline is very much required to successfully deploy the right methods and tools in project decision. To understand the possible effects of a project in a portfolio and eventually make a better decision, project portfolio managers should deploy appropriate PPM processes and tools (Shenhar, Dvir, Levy \& Maltz, 2001), although individual customization may be required to achieve the best results (Loch, 2000). An organization needs to develop and combine the right process and the right culture, which, in turn, will enable it to effectively learn from past experiences (Williams, 2007). Regarding the OTT business, providing the right methodology and tools is a suitable PPM practice, and it would be gradually improving if a cultural approach is also deployed.

\subsection{Resource Limitation}

In common practices, a firm is required to allocate its limited resources to support only feasible projects and to ensure that most beneficial projects are selected. Researchers and practitioners have developed many models, methods, guidelines, and techniques to select projects or initiatives for portfolio inclusion with the intention to maximize benefits and minimize expenses. As Meyer (2012) explains, resources are considered a very important factor to determine project inclusion in a portfolio. The technique is deployed by putting all feasible projects in 
priority order according to certain predetermined criteria. The ranked feasible projects will be truncated according to the availability of the resources. An example of this technique is proposed by Archer and Ghasemzadeh (1999) in these three consecutive steps:

1. Eliminate unfeasible projects prior to the portfolio selection process.

2. Create desirability ranking of the projects by simultaneously comparing them based on predetermined dimensions.

3. Include most highly ranked projects in the portfolio according to the available resources.

As has been discussed in this literature review, the approach proposed by Archer and Ghasemzadeh (1999) neglects possible contributions of apparently non-feasible projects and therefore may miss the opportunity to achieve the best portfolio.

\subsection{Special Case of OTT Initiatives}

The emerging and unique OTT business requires special treatment due to its liquidity, externality and interdependency natures. During the strategy development phase of the OTT business, portfolio managers may also consider objectives that are not directly related to financial measures such as providing support for other OTT services, obtaining strategic position or pursuing market capitalization. Similarly, interdependency in the OTT context refers to technical interdependency, which regards how one OTT service can support other OTT services regardless of the financial aspects.

Both perspective and criteria in project selection techniques are dominated by strategic, financial and risk indicators (Bitman \& Sharif, 2008). The indicators' summary implies that much previous research focuses heavily on accuracy and validity. Consequently, apparently non-performing interdependent projects will be eliminated. To address the specific case of OTT initiatives with their interdependent characteristics, a comparison among the various earlier research in portfolio analysis is constructed with four main focuses: linkage to strategy objective, dominance of financial criteria, portfolio selection process and prioritizing system, as shown in Table 1. Similar to the previous research, this paper proposes that the linkage to the strategy objective is very important; in addition, regarding the financial perspective, this paper suggests margin and particularly investment structure as criteria for consideration. In contrast to other research, this paper has a hypothesis that the overall portfolio should be analyzed before the evaluation of individual initiatives and proposes considering technical interdependency in the prioritizing system.

\begin{tabular}{|c|c|c|c|c|}
\hline Authors & $\begin{array}{l}\text { Linkage to } \\
\text { strategic } \\
\text { objectives }\end{array}$ & $\begin{array}{c}\text { Financial } \\
\text { criteria }\end{array}$ & $\begin{array}{l}\text { Portfolio } \\
\text { selection process }\end{array}$ & $\begin{array}{l}\text { Prioritizing } \\
\text { system }\end{array}$ \\
\hline Gray and Larson (2011) & $\sqrt{ }$ & $\sqrt{ }$ & & $\begin{array}{l}\text { Alignment to organization } \\
\text { strategy implementation }\end{array}$ \\
\hline Eliat et al. (2008) & $\sqrt{ }$ & $\sqrt{ }$ & & Balanced Scorecard \\
\hline $\begin{array}{l}\text { Archer and Ghasemzadeh } \\
\text { (1999) }\end{array}$ & $\sqrt{ }$ & $\sqrt{ }$ & $\begin{array}{l}\text { Individual project } \\
\text { then overall portfolio }\end{array}$ & $\begin{array}{c}\text { Resource interdependency and } \\
\text { limitation }\end{array}$ \\
\hline PMI (2008) & & & $\begin{array}{l}\text { Individual project } \\
\text { then overall portfolio }\end{array}$ & \\
\hline Yu et al. (2008) & $\sqrt{ }$ & & $\begin{array}{l}\text { Individual project } \\
\text { then overall portfolio }\end{array}$ & \\
\hline Liesio et al. (2008) & & & & $\begin{array}{c}\text { Resource interdependency and } \\
\text { limitation }\end{array}$ \\
\hline Turner (2009) & $\sqrt{ }$ & $\sqrt{ }$ & & Benefit and risk \\
\hline Lawson et al. (2006) & & $\sqrt{ }$ & & \\
\hline
\end{tabular}




\begin{tabular}{|c|c|c|c|c|}
\hline Authors & $\begin{array}{l}\text { Linkage to } \\
\text { strategic } \\
\text { objectives }\end{array}$ & $\begin{array}{l}\text { Financial } \\
\text { criteria }\end{array}$ & $\begin{array}{l}\text { Portfolio } \\
\text { selection process }\end{array}$ & $\begin{array}{l}\text { Prioritizing } \\
\text { system }\end{array}$ \\
\hline $\begin{array}{l}\text { Jafarizadeh and Khorshid- } \\
\text { Doust (2008) }\end{array}$ & & $\sqrt{ }$ & & \\
\hline Murray et al. (2009) & $\sqrt{ }$ & $\sqrt{ }$ & $\begin{array}{l}\text { Individual project } \\
\text { then overall portfolio }\end{array}$ & $\begin{array}{l}\text { Simpler qualitative method } \\
\text { involves non-financial criteria }\end{array}$ \\
\hline De Maio et al. (1994) & & & & Key people \\
\hline Jiang and Klein (1999) & $\sqrt{ }$ & & & \\
\hline Kester et al. (2009) & $\sqrt{ }$ & & & $\begin{array}{l}\text { Quantitative and qualitative } \\
\text { methods }\end{array}$ \\
\hline Bergman and Mark (2002) & $\sqrt{ }$ & & & Requirements analysis \\
\hline Muller et al. (2008) & $\sqrt{ }$ & & & Selecting and prioritizing \\
\hline Jung (2009) & & & & $\begin{array}{l}\text { Balancing quantitative and } \\
\text { qualitative methods/criteria }\end{array}$ \\
\hline Bathallath et al. (2016) & $\begin{array}{l}\text { Optimizing } \\
\text { resource }\end{array}$ & $\begin{array}{c}\text { Effects of } \\
\text { interdependency }\end{array}$ & & $\begin{array}{l}\text { Interdependency and interaction } \\
\text { pattern }\end{array}$ \\
\hline Proposed in this paper & $\sqrt{ }$ & $\begin{array}{l}\text { Margin and } \\
\text { investment } \\
\text { structure }\end{array}$ & $\begin{array}{l}\text { Overall portfolio then } \\
\text { individual project }\end{array}$ & $\begin{array}{l}\text { Technical interdependency, } \\
\text { initiatives with more dependence } \\
\text { are preferred }\end{array}$ \\
\hline
\end{tabular}

Table 1. Comparison of Various Portfolio Selection Techniques

In considering specific characteristics of OTT initiatives, Table 2 below is constructed to directly contrast common portfolio selection as suggested by Archer and Ghasemzadeh and specific OTT portfolio selection. The table contrasts the two perspectives in six aspects: strategic orientation, interdependency, resource limitation, selection approach/method, selection complexity and selection sequence. The proposal from Muray et al. (2009) to simplify the evaluation process and to use qualitative information is also considered.

\begin{tabular}{|c|c|c|}
\hline & $\begin{array}{l}\text { Conventional Portfolio Selection } \\
\text { (Archer and Ghasemzadeh) }\end{array}$ & OTT Portfolio Selection \\
\hline Strategic orientation & Based on direct financial impacts & $\begin{array}{l}\text { Based on direct or indirect financial } \\
\text { impacts }\end{array}$ \\
\hline Interdependency & $\begin{array}{l}\text { Interdependency in the context of resource } \\
\text { allocation and time or project sequence } \\
\text { (resource interdependency) }\end{array}$ & $\begin{array}{l}\text { Interdependency in the context of } \\
\text { influence from one OTT service to } \\
\text { another (technical interdependency) }\end{array}$ \\
\hline Resource limitation & As criteria to select project in the portfolio & As an opportunity for collaboration \\
\hline Selection approach/method & Primarily quantitative & $\begin{array}{c}\text { Combination of simple qualitative and } \\
\text { simple quantitative }\end{array}$ \\
\hline Selection complexity & Can be very complex & Must be made simpler \\
\hline Selection sequence & Individual project then overall portfolio & $\begin{array}{c}\text { Consider overall portfolio then evaluate } \\
\text { individual project }\end{array}$ \\
\hline
\end{tabular}

Table 2. Comparison between Conventional Portfolio Selection and OTT Portfolio Selection 


\section{Methodology}

The research adopts the group model-building (Vennix, Anderson, Richardson \& Rohrbaugh, 1992; Vennix 1996, Andersen \& Richardson, 1995; Andersen \& Richardson, 1997; Andersen, Richardson \& Vennix, 1997) methodology to identify the need for the adjustment of common PPM and to propose a new PPM specifically adjusted for the OTT initiative development process. To gain information regarding the effectiveness of common PPM and to test the new PPM, the research includes in-depth interviews, questionnaires, and focus group discussions (FGDs) with participants who have been working on more than fifty OT'T initiatives in total. The indepth interviews involve top-level executives, while both questionnaires and FGDs involve strategic-level business managers. The research is conducted at one of the largest CSPs in the Asia Pacific region.

In-depth interviews with seven top-level executives of the CSP both at the group holding and the subsidiary levels are conducted to assess their perspectives and concerns regarding the current portfolio construction process in which OT'T initiatives are evaluated and selected into the portfolio. Potential advantages of a newly designed PPM approach and conditions to be met are also discussed. The questionnaires are intended to obtain an initial opinion about the need to adjust the existing PPM process to make it more suitable for the OTT initiative selection process. Forty respondents at the strategic level are provided closed 'Yes' or 'No' questions. The questions are arranged in such a manner that certain responses to the previous questions may refer to certain answers in the ensuring questions. If any inconsistency is identified, further confirmation will be made.

Eight respondents who consistently agree that the overall portfolio should be constructed first before evaluating individual initiatives are then selected to participate in two FGD sessions. The selection of respondents also considers their position either at the group level or at the subsidiary level, and either they are managing portfolios (portfolio manager) or initiatives (project manager). The schedule match and availability of the respondents are also considered. The FGD consists of two sessions to assess respondents' opinions toward the need for evaluating interdependent initiatives simultaneously rather than individually and the need for deploying the group model-building (GMB) approach. The ultimate objective of the FGD is to construct a new approach to simultaneously evaluate OTT initiatives. Therefore, participants are stimulated to use a dependency matrix and consider all interdependent initiatives at once. Upon the OTT PPM modification is completed, participants are invited to use the model to evaluate OTT initiatives within their responsibility. Prompt participant feedback is solicited immediately thereafter.

\section{Findings}

In general, all top-level executives agree that the current PPM process in the OTT situation needs to be improved with emphasis on interdependency impacts. Three top-level executives expect the PPM to become more ecosystem-oriented by considering other related initiatives in the portfolio, which are in alignment with the idea of interdependency. Similarly, one executive states that a more integrated development model that stimulates coordination across various related functions is very much expected. Two executives expect PPM to become more accurate and faster in facilitating decision making with a tolerance for failure. A tool to help executives find partners and create partnership deals particularly with a global partner is also expected. In conclusion, the executives need a more integrated, systematic, accurate and simple approach to OT'T portfolio construction.

Interdependency is very important, and it has been considered during the evaluation process of the OTT initiative portfolio as confirmed by six executives. One executive states that certain OTT services, such as music and movies, involve strong interdependency, while other OTT services, such as games, travel and shopping, involve moderate interdependency. All top-level executives realize that a single OTT initiative is nearly impossible. The executives also agree that interdependency is very impactful and important to consider but remains under-utilized in the initiative selection process. The top-level executives are concerned that the current process potentially misses the importance of interdependency. One concern also highlights as an example a video call that was not as successful but had high interdependency with e-learning. One top-level executive suggests forming a committee to purposefully review interdependency. Another top-level executive urges sharpening assumptions in project selection when using a portfolio evaluation matrix such as a BCG or GE matrix. In summary, the top-level executives expect to achieve optimum OTT initiative portfolio as it has become the objective of the PPM in general (Archer \& Ghasemzadeh, 
1999) and in alignment with strategic objectives of the CSP (Jiang \& Klein, 1999), given the challenge of interdependency and limited resources.

Preliminary questionnaires were distributed to confirm the concerns at the strategic level. The questionnaires ask six relevant questions, as shown in Figure 2, to thirty-six business managers who work in various business lines and who have been initiating various OTT initiatives both at the group holding level and in subsidiaries. The questionnaires are also distributed to four external consultants who have global experience in providing consulting to various CSPs to manage OTT initiatives for comparison purposes. From Figure 2 below, it can be recognized that the dominant portion of respondents are specialized in evaluating individual projects (initiative) first. After further clarification, the remaining portion of the respondents who are not specialized in evaluating individual initiatives explain that their answers represent their thoughts and not their actual practice. This clarification concludes that, in the current practice, all respondents normally evaluate each individual project first. While financial indicators are solely used as determinants for OTT initiative selection, the dominant portion of respondents believe that certain OTT initiatives are not financially feasible but should be included in the portfolio because they are required by other OTT initiatives. The remainder who do not agree with this statement are respondents who are actually responsible for project funding or business acquisition; in addition, apparently, the financial perspective has become their primary concern. Based on the logic sequence as requested in the questionnaire, it can be concluded that technical interdependency does exist; this is confirmed by all respondents. Most respondents conclude that, due to technical interdependency, construction of the overall portfolio should occur prior to the evaluation of an individual OTT initiative regardless of its financial feasibility. This finding is in contrast to framework of PPM suggested by Archer and Ghasemzadeh (1999).

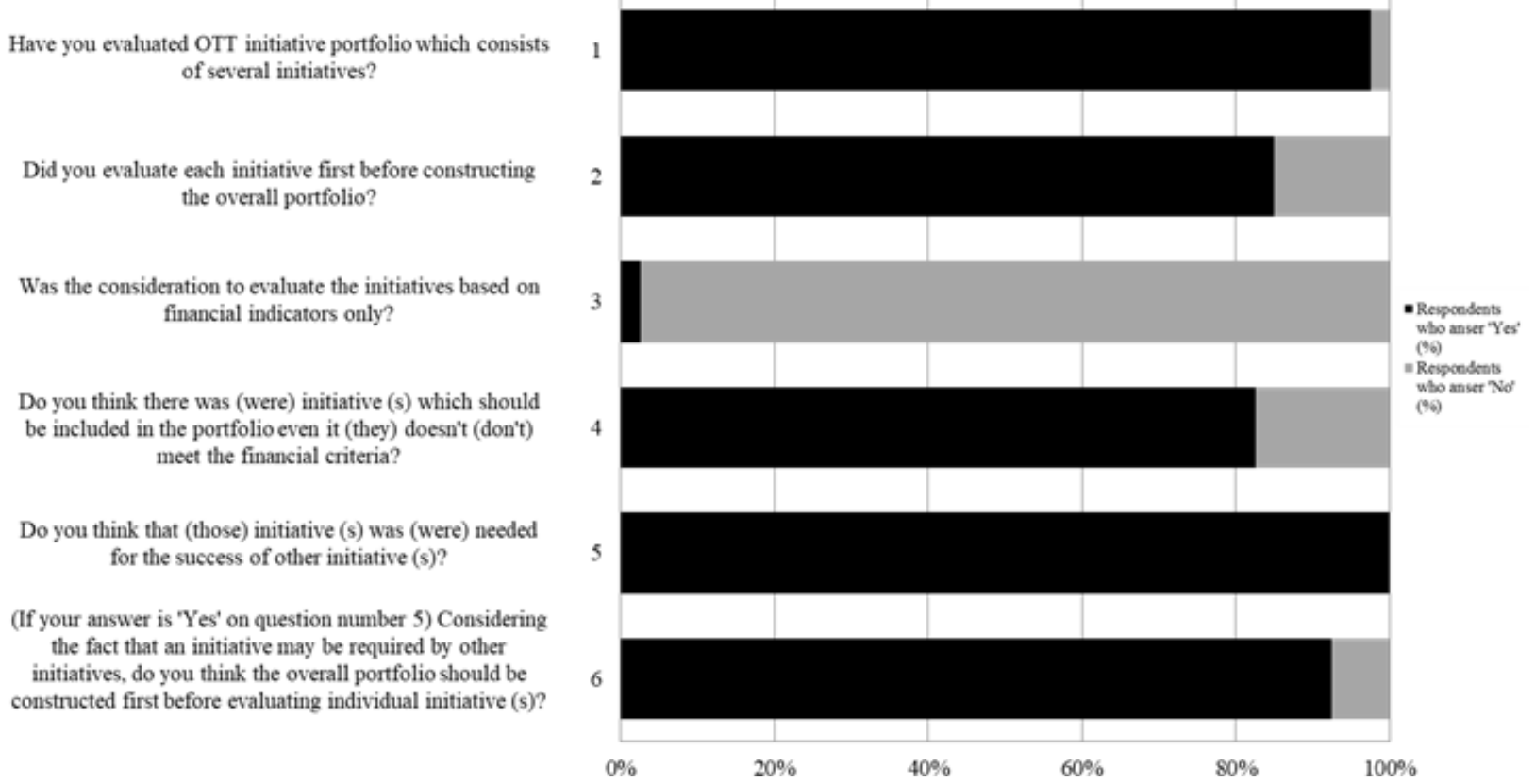

Figure 2. Questionnaire Results on Portfolio Selection Process for OTT Initiatives

To examine if the overall portfolio can be constructed prior to the evaluation of the individual OTT initiative, eight respondents who support the premise are selected to join the FGD sessions. The FGDs are conducted twice in two different sessions. In the first session, all respondents reconfirm that interdependency strongly influences the success of most OT'T initiatives since, in the OT'T world, it is very rare to find a single independent service. This finding explains the role of technical interdependency (Bathallath et al., 2016) in OTT initiatives. All respondents also agree that the construction of an overall OTT initiative portfolio should occur prior to individual evaluation to provide more reliable decisions. This finding is also in contrast to Archer and Ghasemzadeh (1999) on project selection process. The second session deploys the GMB approach to examine if an overall portfolio can be 
constructed by including interdependency. Respondents are requested to use a dependency matrix (Dickinson et al., 2001; Slade, 2009) for assessing the interdependency of all initiatives they are currently working on. The results are then mapped into a two by two matrix with business attractions on the $\mathrm{X}$-axis and business barriers on the Y-axis. To assist the respondent in the simulation, a set of selection rules of interdepender OT'T initiatives are established as follows:

1. An initiative that provides influence on another initiative is defined as interdepender, and an initiative that receives influence from another initiative is defined as interdependant.

2. One interdepender may influence more than one interdependants, and one interdependant may receive influence from more than one interdependers.

3. If an interdependant is selected, all its interdependers must also be selected into the portfolio to ensure that the interdependant will be successfully implemented. In contrast, if an interdepender is selected, it does not mean all its interdependants must be selected. Unfeasible interdependants should not be selected into the portfolio unless they also become interdependers to other selected initiatives.

After all initiatives are fairly selected using this new specific rule, the respondents are requested to evaluate the feasibility of the portfolio. To ensure fair analysis, an interdepender may be included in another interdependant's financial analysis. However, since an interdepender may influence several interdependants, there is a possibility that the same interdepender is being evaluated several times and therefore misleadingly increases the amount of investment. To avoid such miscalculation, the FGD respondents agree to use one of the two following options for project financial analysis purposes:

1. Largest interdependant in terms of financial investment or an interdependant that primarily uses the interdepender's service could be selected as the one that bears the interdepender's expenses.

2. The interdepender's expenses are shared proportionally with all its interdependants, according to their usage.

\section{Discussion}

Based on the empirical findings as explained above, the research concludes that an OTT initiative is very unique because it involves a high degree of technical interdependency. In addition, the research confirms that the overall OTT initiative portfolio should be constructed prior to an individual initiative evaluation. The research proposes the following steps to construct a portfolio of OTT initiatives:

1. Candidate list of OT'T initiatives

2. Interdependency diagram

3. Evaluation of all interdependent OT'T initiatives

4. Evaluation of all non-interdependent OTT initiatives

5. Optimal portfolio that consists of interdependent and non-interdependent (single) OTT initiatives

The proposed steps to construct a portfolio of OTT initiatives begin with listing the candidates of OTT initiatives. All initiative ideas can be included in this step. Each initiative should be equipped with clear information regarding the purpose, the technical capability and its requirement, particularly those that relate to other OTT initiatives. The second step specifically addresses the need to map all candidates into an interdependency diagram, as shown in Figure 3, by first constructing a dependency matrix, as shown in Table 3.

Using the dependency matrix, project portfolio managers can identify which OTT initiatives are needed by other OTT initiatives. OTT initiatives that are interdependent should be clustered and considered as simultaneous initiatives. If there is (are) an OTT initiative(s) that is (are) needed by more than one different cluster, that (those) initiative(s) will be considered a platform(s). To obtain a better picture of the cluster and platform, Figure 3 below provides an illustrative example that has three clusters, as follows: 
- Cluster 1: Network Verification, ID Verification, Payment Service, Chat and Messaging Service, Media Hub, and Music Streaming

- Cluster 2: Network Verification, ID Verification, Payment Service, Chat and Messaging Service, Media Hub, and Video Streaming

- Cluster 3: Network Verification, ID Verification, Payment Service, Chat and Messaging Service, and Online Store

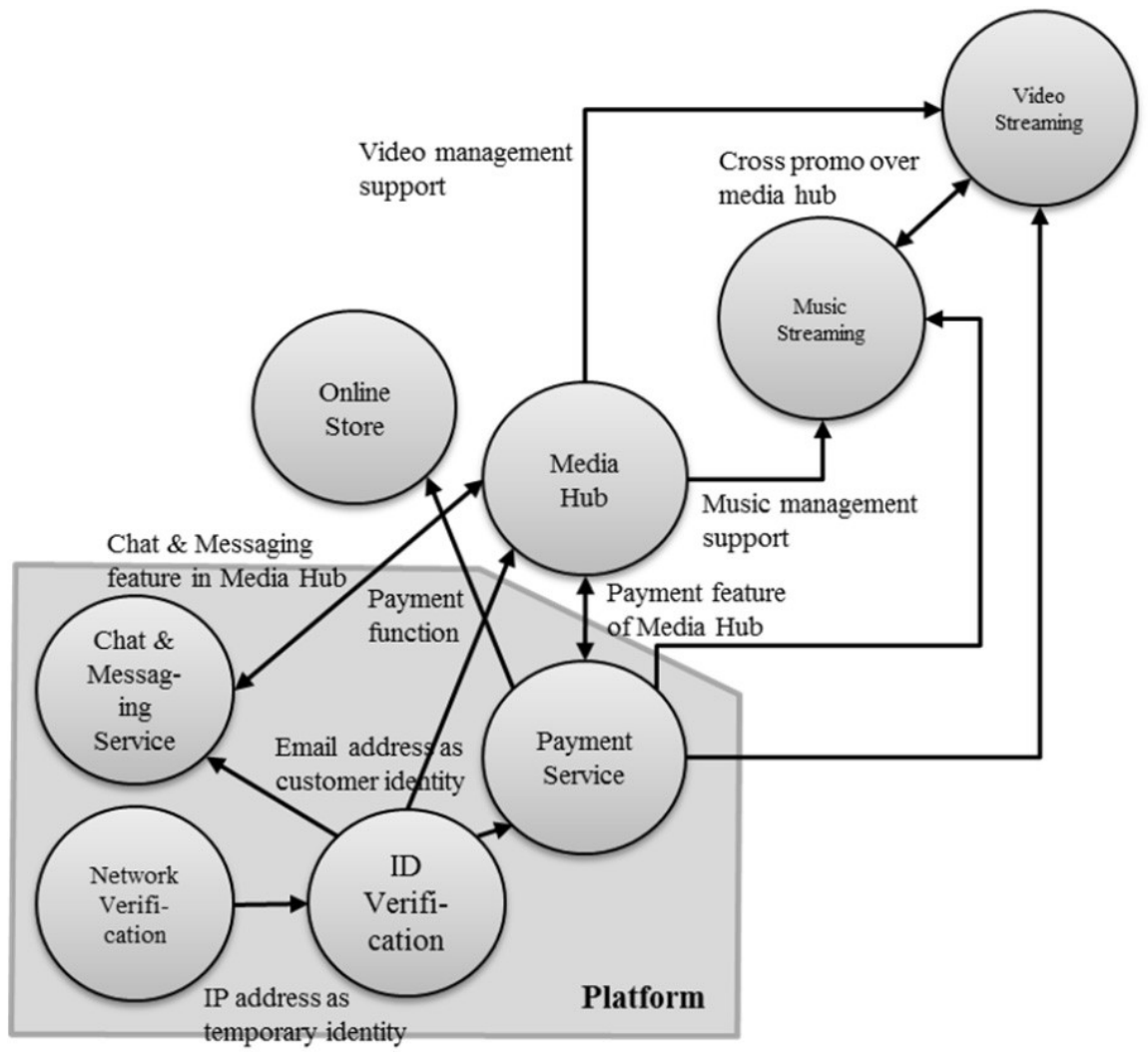

Figure 3. An Example of OTT Initiative Portfolio using Dependency Relationship

\begin{tabular}{|c|c|c|c|c|c|c|c|c|}
\hline & $\begin{array}{c}\text { Network } \\
\text { verification }\end{array}$ & $\begin{array}{c}\text { ID } \\
\text { verification }\end{array}$ & $\begin{array}{l}\text { Payment } \\
\text { service }\end{array}$ & $\begin{array}{c}\text { Chat } \& \\
\text { messaging } \\
\text { service }\end{array}$ & $\begin{array}{l}\text { Media } \\
\text { hub }\end{array}$ & $\begin{array}{l}\text { Online } \\
\text { store }\end{array}$ & $\begin{array}{c}\text { Music } \\
\text { streaming }\end{array}$ & $\begin{array}{c}\text { Video } \\
\text { streaming }\end{array}$ \\
\hline $\begin{array}{l}\text { Network } \\
\text { verification }\end{array}$ & & $\sqrt{ }$ & & & & & & \\
\hline ID verification & & & $\sqrt{ }$ & $\sqrt{ }$ & $\sqrt{ }$ & & & \\
\hline Payment service & & & & & $\sqrt{ }$ & $\sqrt{ }$ & $\sqrt{ }$ & $\sqrt{ }$ \\
\hline $\begin{array}{l}\text { Chat \& messaging } \\
\text { service }\end{array}$ & & & & & $\sqrt{ }$ & & & \\
\hline Media hub & & & $\sqrt{ }$ & & & & $\sqrt{ }$ & $\sqrt{ }$ \\
\hline Online store & & & & & & & & \\
\hline Music streaming & & & & & & & & $\sqrt{ }$ \\
\hline Video streaming & & & & & & & $\sqrt{ }$ & \\
\hline
\end{tabular}

Table 3. Illustration of a Dependency Matrix 
In this example, Network Verification, ID Verification, Payment Service and Chat and Messaging Service construct a platform that provides basic functions for all other OTT services; therefore, all those initiatives should be included in the platform. The inclusion of initiatives into a platform may differ according to the firm's policy. For instance, in Figure 3, media hub can be considered a platform with network verification, ID verification, payment service and chat and messaging service as its features; alternatively, certain services can be excluded from the platform and treated as single initiatives. Furthermore, the manner in which a cluster is evaluated is equivalent to evaluating all OTT initiatives in that cluster. Similarly, the total resources allocated to a cluster are equivalent to the sum of resources allocated to all OTT initiatives in that cluster. However, if several clusters utilize the same platform, to avoid double counting and to maintain a fair evaluation, the cost of the platform can be covered by the largest cluster that uses the platform most frequently or proportionally shared with all clusters. Consequently, the financial evaluation of the platform should be derived from financial projections of the clusters using its services.

It could be that several non-interdependent OTT initiatives are selected due to their business potentials. Those OTT initiatives are not dependent on other OTT initiatives and are considered separate single initiatives. These single initiatives could be evaluated and included in the portfolio based on business and technical considerations. The OTT initiative portfolio can be considered final when the cluster of interdependent OTT initiatives, platforms and single initiatives have been evaluated and selected.

Eight FGD participants attempted to apply the proposed steps to select OT'T initiatives they were currently working on, which, in turn, resulted in eight OTT initiatives. Five samples from the FGD, which primarily have interdependency characteristics, are selected for further discussion as depicted in Figures 4 to 8 and explained in Table 4. Further clarifications were also made to each respondent to ensure all arrows are drawn properly. Specific clarification was performed for every bidirectional arrow to ensure the initiatives are reciprocally interdependent. The application of the proposed five steps has made identification of interdependers possible. All samples require e-Payment as an interdepender, including Sample 4, which needs it to run Home Shopping, Cloud Game and OT'T Video services. Two initiatives, Home Store in Sample 3 and Home Shopping in Sample 4, are actually the same. This redundancy occurs due to the absence of a proper portfolio selection tool and insufficient coordination.

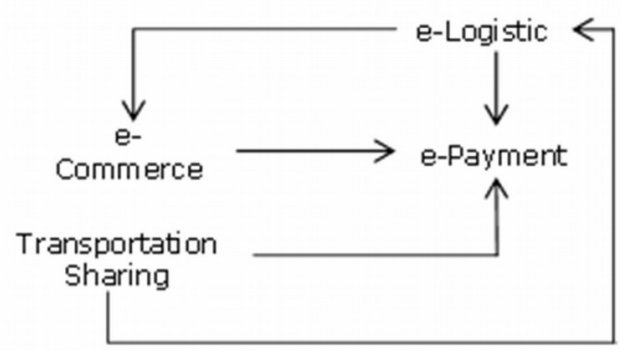

Figure 4. Sample 1 of E-Logistic Initiative

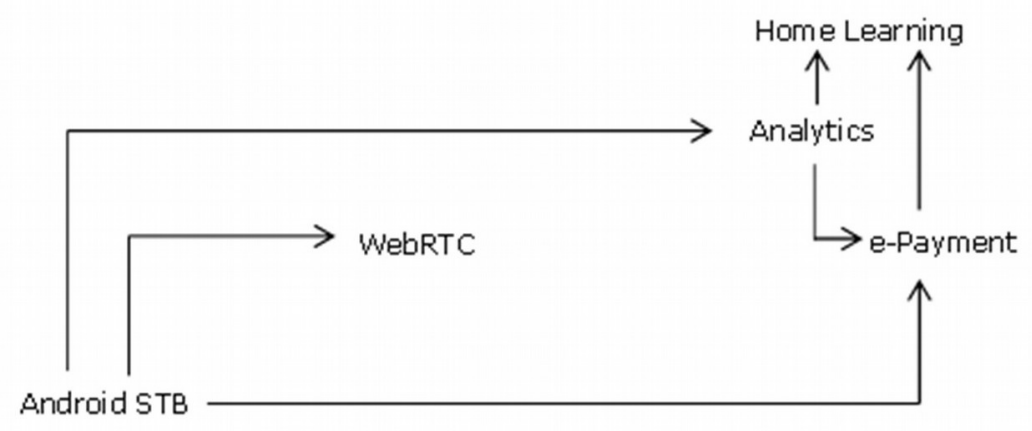

Figure 5. Sample 2 of Home Learning Initiative 


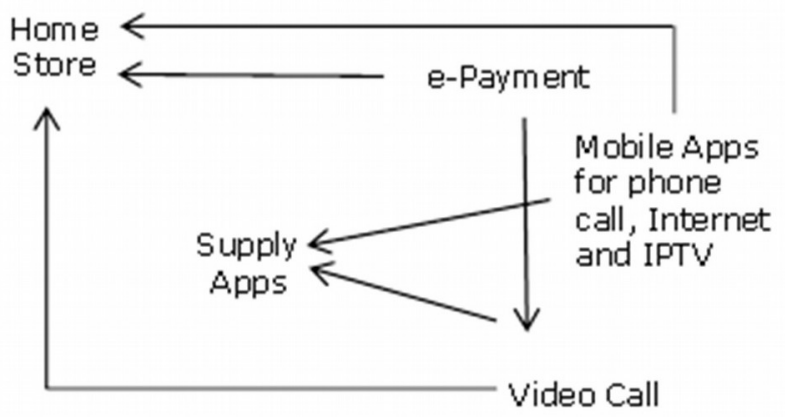

Figure 6. Sample 3 of Home Store Initiative

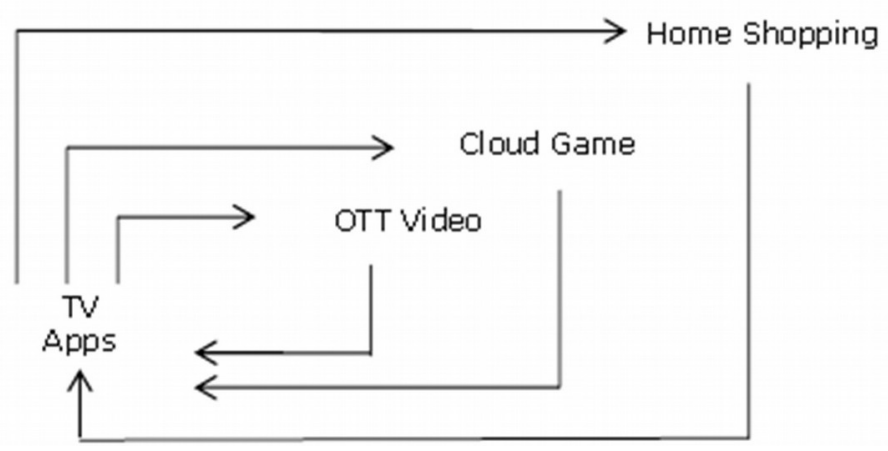

Figure 7. Sample 4 of Home Shopping Initiative

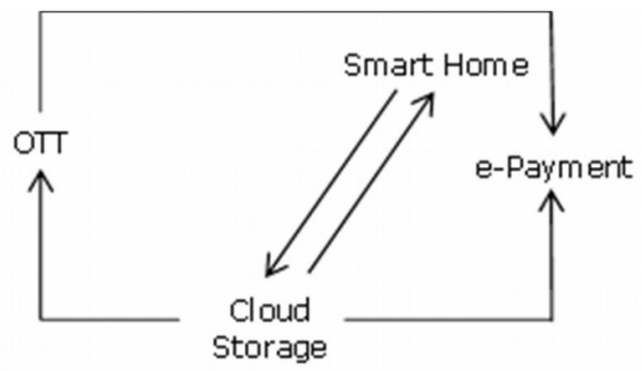

Figure 8. Sample 5 on Smart Home Initiative

\begin{tabular}{|c|l|l|}
\hline No & \multicolumn{1}{|c|}{ Initiatives } & \multicolumn{1}{c|}{ Description } \\
\hline 1 & E-Logistic & $\begin{array}{l}\text { Internet-based logistic application that supports an e-commerce system accessible through } \\
\text { web site and mobile application. }\end{array}$ \\
\hline 2 & Home Learning & $\begin{array}{l}\text { Learning application and content delivered through an android set top box (STB) connected } \\
\text { to a television set in customer's house. }\end{array}$ \\
\hline 3 & Home Store & $\begin{array}{l}\text { Shopping application accessible through a mobile phone and a television screen equipped } \\
\text { with logistics and communication facilities. }\end{array}$ \\
\hline 4 & Home Shopping & Shopping application accessible through a television screen equipped with a cloud platform. \\
\hline 5 & Smart Home & $\begin{array}{l}\text { Cloud-based service that enables a customer to control home appliances and devices from a } \\
\text { mobile phone. }\end{array}$ \\
\hline
\end{tabular}

Table 4. Description of Selected OT'T Initiatives 
For OTT initiative portfolio analysis purposes, the step to construct an interdependency diagram can be halted here. However, to address additional research questions, the process is continued. All initiatives from the five samples are placed together on the same chart. After interdependency lines were redrawn, new interdependencies across different units were identified, as shown in Figure 9.

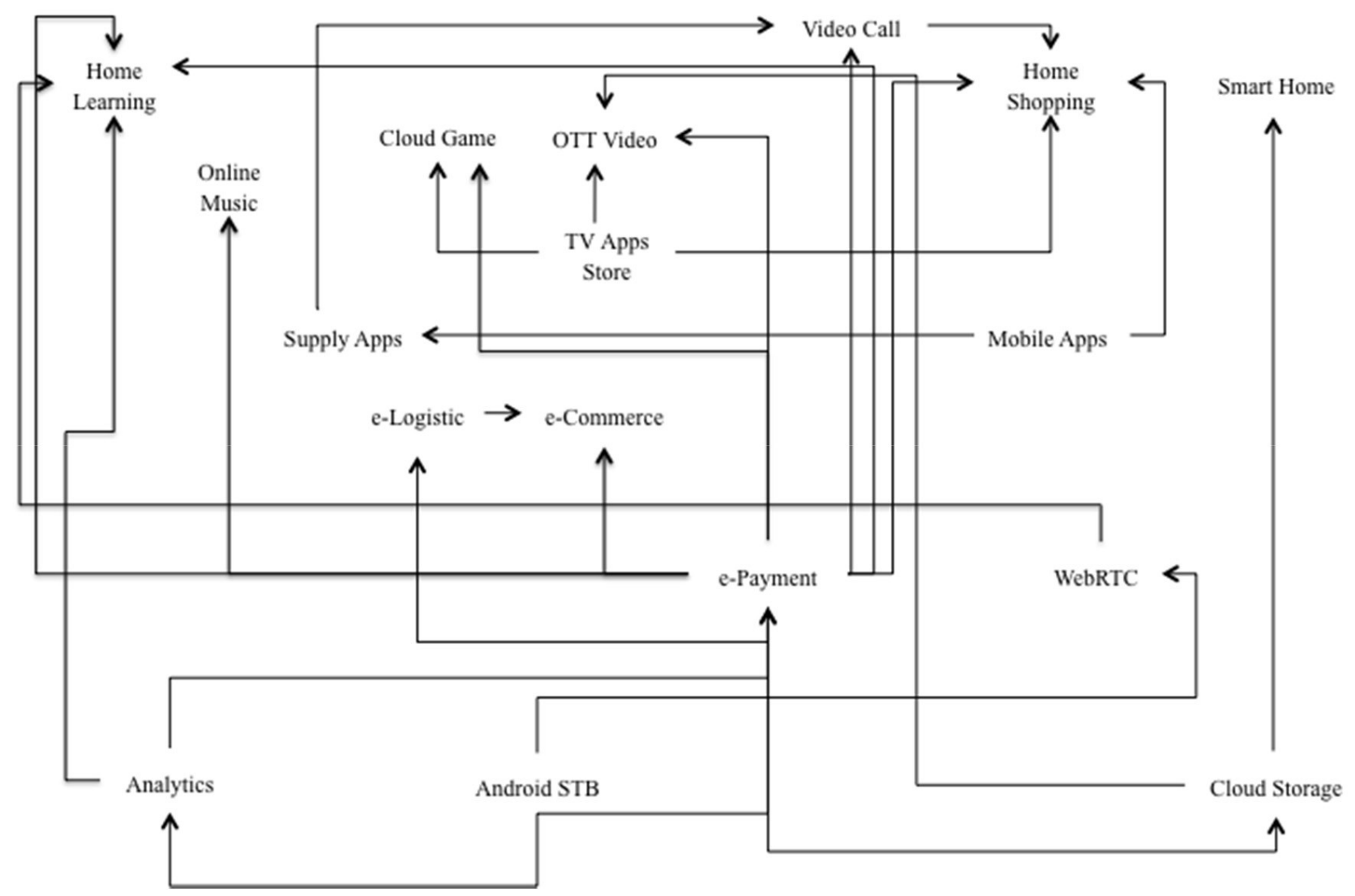

Figure 9. Combination of All Initiatives from Five Respondents

From Figure 9, it can be quickly identified that there are 7 clusters: Home Learning, Online Music, Cloud Game, OTT Video, Home Shopping, Smart Home and e-Commerce. These initiatives are the final services to customers. The other initiatives become interdepender to the cluster head, which only receives support and does not provide support to other initiatives. Among the initiatives, e-Payment and TV Apps Store are the most needed initiatives. EPayment is an interdependant of Analytics and Android Set Top Box; therefore, these four initiatives must be included in the platform regardless of their financial performances.

After completing the newly proposed OTT initiative selection process, the respondents are requested to provide feedback using the Technology Acceptance Model (TAM) from Davis (1989), which consists of perceived usefulness (PU) and perceived ease of use (PEOU) aspects. The questions in the TAM feedback form are modified to make them relevant to the OTT initiative selection process. Nearly all respondents provide positive feedback to this newly proposed OTT initiative selection approach for PU-relevant aspects; the feedback includes comments such as more accurate evaluation, better anticipation of challenges and very helpful in making the OTT initiative decision. Respondents also provide relatively positive feedback for the PEOU relevant aspects; the feedback includes comments such as easy to learn, easy to remember, and has clarity and understandability.

\section{Conclusion and Recommendation}

Common practices in portfolio selection, which suggest evaluating individual project prior to portfolio construction, do not fit the OTT initiative portfolio selection performed by CSPs due to specific OTT characteristic such as interdependency. The empirical research using GMB, which involves an in-depth interview, 
questionnaires and FGD from top-level executives and strategic-level business managers in one of the largest CSPs in the Asia Pacific region and several consultants in the OTT field, indicates that a different approach in constructing the OTT initiative portfolio is required. This paper suggests the following five distinct steps to construct the OTT initiative portfolio: a candidate list of OTT initiatives, an interdependency diagram, an evaluation of all interdependent OTT initiatives, an evaluation of all non-interdependent OTT initiatives and an optimal portfolio of OTT initiatives. The five steps to construct the OTT initiative portfolio as suggested in this research is in alignment with Tasevska et al. (2013) who suggest to apply a combination of both hard and soft practices to deal with interdependency. The hard practice is applied using the dependency matrix and the interdependency diagram as part of the procedure that should become the soft practice of the CSP in the portfolio selection process.

The inclusion of interdepender OTT initiatives in the portfolio regardless of their individual profitability implies that the financial aspect is no longer the primary consideration in the selection process as also suggested by Murray et al. (2009). In alignment to Killen and Kjaer (2012), the research confirms that the use of graphical and visual methods such dependency matrix (Dickinson et al., 2001; Slade, 2009) and interdependency diagram is very helpful for a CSP to address the unique characteristics of OTT initiatives in the portfolio construction process. This research also suggests a simple method to identify a cluster of OT'T initiatives in which all interdependent OTT initiatives are evaluated simultaneously for their inclusion into a portfolio. This method can also be used to identify the presence of a platform. To avoid double counting, platform evaluation can be included in a cluster that most frequently uses the platform; alternatively, it can be distributed proportionally to all OTT initiatives that use the platform. Single OTT initiatives could also be included in the OTT initiative portfolio if the initiatives are feasible according to agreed upon criteria.

The management of the OT'T initiative portfolio is relatively new to the academic perspective; therefore, theories related to the subject are not well established yet. For further development, the proposed approach to construct an OTT initiative portfolio needs to be examined by comparing results of the conventional approach and results of this proposed OTT-specific approach. This proposed approach to construct an OTT initiative portfolio could also be deployed in a non-OTT portfolio as long as the projects being evaluated possess interdependency characteristics. However, considering the limitations of empirical research being used as the basis of the conclusion, the generalization of this approach will require further empirical tests in different CSPs, OTT players or any firms performing portfolio selection.

\section{Declaration of Conflicting Interests}

The authors declared no potential conflicts of interest with respect to the research, authorship, and/or publication of this article.

\section{Funding}

The authors received no financial support for the research, authorship, and/or publication of this article. 


\section{References}

Andersen, D.F., \& Richardson, G.P. (1995). Teamwork in Group Model-Building. System Dynamics Review, 11(2), 113137. https://doi.org/10.1002/sdr.4260110203

Andersen, D.F., \& Richardson, G.P. (1997). Scripts for Group Model Building. System Dynamics Review, 13(2), 107-129. https://doi.org/10.1002/(SICI)1099-1727(199722)13:2<107::AID-SDR120>3.0.CO;2-7

Andersen, D.F., Richardson, G.P., \& Vennix, J.A.M. (1997). Group Model Building: Adding More Science to the Craft. System Dynamics Review, 13(2), 187-201. https://doi.org/10.1002/(SICI)1099-1727(199722)13:2<187::AIDSDR124>3.0.CO;2-O

Archer, N.P., \& Ghasemzadeh, F. (1999). An Integrated Framework for Project Portfolio Selection. International Journal of Project Management, 17(4), 207-216. Published by Elsevier Science Ltd. and IPMA. https://doi.org/10.1016/S0263-7863(98)00032-5

Archer, N., \& Ghasemzadeh, F. (2004). Project Portfolio Selection and Management. In Morris, P.W.G., \& Pinto, J.K. (Eds.), The Wiley guide to managing projects (237-255). Hoboken, NJ: John Wiley \& Sons, Inc. https://doi.org/10.1002/9780470172391.ch11

Aritua, B., Smith, N.J., \& Bower, D. (2009). Construction client multi-projects - A complex adaptive systems perspective. International Journal of Project Management, 27(1), 72-79. https://doi.org/10.1016/j.ijproman.2008.02.005

Armstrong, M. (2006). Competition in Two-Sided Markets. Rand Journal of Economics, 37(3), 668-691. https://doi.org/10.1111/j.1756-2171.2006.tb00037.x

Bathallath, S., Smedberg, A., \& Kjellin, H (2016). Managing Project Interdependencies in IT/IS Project Portfolios: A Review of Managerial Issues. International Journal of Information Systems and Project Management, 4(1), 2016, 67-82.

Bergman, M., \& Mark, G. (2002). Exploring the Relationship between Project Selection and Requirements Analysis: An Empirical Study of the New Millennium Program. Joint International Conference on Requirements Engineering (RE'02). https://doi.org/10.1109/ICRE.2002.1048535

Bitman, W., \& Sharif, N. (2008). A Conceptual Framework for Ranking R\&D Projects. IEEE Transactions on Engineering Management, 55(2), 267-278. https://doi.org/10.1109/TEM.2008.919725

Blau, G.E., Pekny, J.F., Varma, V.A., \& Bunch, R.R. (2004). Managing a Portfolio of Interdependent New Product Candidates in the Pharmaceutical Industry. Journal of Product Innovation Management, 21, 227-245. https://doi.org/10.1111/j.0737-6782.2004.00075.x

Collyer, S., \& Warren, C.M.J. (2009). Project Management Approaches for Dynamic Environments. International Journal of Project Management, 27(4), 355-364. https://doi.org/10.1016/j.ijproman.2008.04.004

Cooper, R.G., Edgett, S.J. \& Kleinschmidt, E.J. (2001). Porffolio Management for New Products. Perseus, Cambridge, Mass.

Davis, F.D. (1989). Perceived Usefulness, Perceived Ease of Use, and User Acceptance of Information Technology. MIS Quarterly, 13, 319-340. https://doi.org/10.2307/249008

De Maio, A., Verganti, R., \& Corso, M. (1994). A Multi-Project Management Framework for New Product Development. European Journal of Operational Research, 78, 178-191. https://doi.org/10.1016/0377-2217(94)90381-6

Dickinson, M.W., Thornton, A.C., \& Graves, S. (2001). Technology Portfolio Management: Optimizing Interdependent Projects over Multiple Time Periods. IEEE Transactions on Engineering Management, 48(4), 518-527. https://doi.org/10.1109/17.969428

Eliat, H., Golany, B., \& Shtub, A. (2008). R\&D Project Evaluation: An Integrated DEA Balanced Scorecard Approach. Omega, 36(5), 895-912. https://doi.org/10.1016/j.omega.2006.05.002 
Elonen, S., \& Artto, K.A. (2003). Problems in Managing Internal Development Projects in Multi-Project Environments. International Journal of Project Management, 21, 395-402. https://doi.org/10.1016/S0263-7863(02)000972

Gray, C.F., \& Larson, E.W. (2011). Project Management: The Managerial Process (3 ${ }^{\text {rd }}$ ed.). New York: McGraw-Hill.

Gupta, S., \& Mela, C.F. (2008). What is a Customer Worth? Harvard Business Review, November.

Gutjahr, W.J., Katzensteiner, S., Reiter, P., Stummer, Ch., \& Denk, M. (2008). Competence-Driven Project Portfolio Selection, Scheduling and Staff Assignment. CEJOR, 16, 281-306. https://doi.org/10.1007/s10100-008-0057-z

Jafarizadeh, B., \& Khorshid-Doust, R.R. (2008). A method of Project Selection Based on Capital Asset Pricing Theories in a Framework of Mean-Semideviation Behavior. International Journal of Project Management, 26, 612-619. https://doi.org/10.1016/j.ijproman.2007.09.004

Jiang, J., \& Klein, G. (1999). Project Selection Criteria by Strategic Orientation. Information and Management, 36, 63-75. https://doi.org/10.1016/S0378-7206(99)00009-9

Jung, J.Y. (2009). Operational Improvement Project Management: Categorization and Selection. Journal of the International Academy for Case Studies, 15(4), 61-66.

Kester, L., Hultink, E.J., \& Lauche, K. (2009). Portfolio Decision-Making Genres: A Case Study. Journal of Engineering and Technology Management, 26, 327-341. https://doi.org/10.1016/j.jengtecman.2009.10.006

Kerzner, H. (2009). Project Management: A Systems Approach to Planning, Scheduling, and Controlling (10 ${ }^{\text {th }} \mathrm{ed}$.). New Jersey: John Wiley \& Sons, Inc.

Killen, C.P., \& Hunt, R.A. (2010). Dynamic Capability through Project Portfolio Management in Service and Manufacturing Industries. International Journal of Managing Projects in Business, 3(1), 157-169.

https://doi.org/10.1108/17538371011014062

Killen, C.P, \& Kjaer, C. (2012). Understanding project interdependencies: The role of visual representation, culture and process. International Journal of Project Management, 30 (2012), 554-566.

https://doi.org/10.1016/j.ijproman.2012.01.018

Lawson, C.P., Longhurst, P.J., \& Ivey, P.C. (2006). The application of a New Research and Development Project Selection model in SMEs. Technovation, 26(2), 242-250. https://doi.org/10.1016/j.technovation.2004.07.017

Levine, H.A. (2005). Project Portfolio Management: A Practical Guide to Selecting Projects, Managing Portfolios, and Maximizing Benefits. San Francisco, CA: Jossey-Bass, John Wiley \& Sons, Inc.

Liesio, J., Mild, P., \& Salo, A. (2007). Preference Programming for Robust Portfolio Modeling and Project Selection. European Journal of Operational Research, 181, 1488-1505. https://doi.org/10.1016/j.ejor.2005.12.041

Liesio, J., Mild, P., \& Salo, A. (2008). Robust Portfolio Modeling with Incomplete Cost Information and Project Interdependencies. European Journal of Operational Research, 190(3), 679-695.

https://doi.org/10.1016/j.ejor.2007.06.049

Loch, C. (2000). Tailoring Product Development to Strategy: Case of a European Technology Manufacturer. European Management Journal, 18, 246-258. https:/ / doi.org/10.1016/S0263-2373(00)00007-4

Martin, E.J. (2012). The Freemium Frenzy. EContent, 35(9), 20-25.

Martinsuo, M., \& Lehtonen, P. (2007). Role of Single-Project Management in Achieving Portfolio Management Efficiency. International Journal of Project Management, 25(1), 56-65. https://doi.org/10.1016/j.ijproman.2006.04.002

Meyer, W.G. (2012). Project Selection and Termination - How Executives Get Trapped. PMI Global Congress Proceedings. Vancouver, Canada.

Moore, S. (2010). Strategic Project Portfolio Management: Enabling a Productive Organization. Hoboken, New Jersey: John Wiley \& Sons, Inc. 
Morgan Stanley Consulting Group (2014). Glossary of Investment Terms. Online Report, 2014-PS-138 2/14.

Morris, P., \& Jamieson, A. (2004). Translating Corporate Strategy into Project Strategy. Newton Square, PA: Project Management Institute.

Muller, R., Martinsuo, M., \& Blomquist, T. (2008). Project Portfolio Control and Portfolio Management Performance in Different Contexts. Project Management Journal, 39(3), 28-42. https://doi.org/10.1002/pmj.20053

Murray, S., Alpaugh, A., Burgher, K., Flachsbart, B., \& Elrod, C.C. (2010). Development of a Systematic Approach to Project Selection for Rural Economic Development. Journal of Rural and Community Development, 5(3), 1-18.

Murray, S.L., Burgher, K., \& Alpaugh, A. (2009). Public Private Partnerships Project Selection Criteria. Industrial Engineering Research Conference.

Needleman, S.E., \& Loten, A. (2012). When Freemium Fails. Wall Street Journal.

Pennypacker, J., \& Retna, S. (Eds.) (2009). Project Portfolio Management: A View from the Management Trenches. Hoboken, New Jersey: John Wiley \& Sons, Inc.

Perminova, O., Gustafsson, M., \& Wikstrom, K. (2008). Defining Uncertainty in Projects: A New Perspective. International Journal of Project Management, 26(1), 73-79. https://doi.org/10.1016/j.ijproman.2007.08.005

Project Management Institute (2008). The Standard for Portfolio Management (2 ${ }^{\text {nd }}$ ed.). Newton Square, PA: Project Management Institute.

Rysman, M. (2009). The Economics of Two-Sided Markets. Journal of Economic Perspectives, 23(9), $125-143$. https://doi.org/10.1257/jep.23.3.125

Shenhar, A.J., Dvir, D., Levy, O., \& Maltz, A.C. (2001). Project Success: A Multidimensional Strategic Concept. Long Range Planning, 34, (6), 699-725. https://doi.org/10.1016/S0024-6301(01)00097-8

Slade, M. (2009). Managing IT Project and Programme Interdependencies across the Home Office. Presentation to the PPM Standards Group. London.

Soderlund, J. (2004). On the Broadening Scope of the Research on Projects: A Review and a Model for Analysis, International Journal of Project Management, 22(8), 655-667. https://doi.org/10.1016/j.ijproman.2004.05.011

Stewart, W. (2001). Balanced Scorecard for Projects. Project Management Journal, 32(1), 38-53.

Stummer, C., \& Heidenberger, K. (2003). Interactive R\&D Portfolio Analysis with Project Interdependencies and Time Profiles of Multiple Objectives. Engineering Management, IEEE Transactions on, 50(2), 175-183. https://doi.org/10.1109/TEM.2003.810819

Tasevska, F., Toropova, O., \& Vanyushyn, V. (2013). Management of Project Interdependencies in a Project Portfolio. Master Thesis. Umea School of Business and Economics.

Turner, J.R. (1999). The Handbook of Project-based Management: Improving the Process for Achieving Strategic Objectives. London: McGraw-Hill.

Turner, J.R. (2009). The Handbook of Project-Based Management - Leading Strategic Change in Organizations (3 ${ }^{\text {rd }}$ ed.). McGraw-Hill.

Vennix, J.A.M. (1996). Group Model-Building: Facilitating Team Learning Using System Dynamics. Chichester: John Wiley \& Sons.

Vennix, J.A.M, Anderson, D.F., Richardson, G.P., \& Rohrbaugh, J. (1992). Model-Building for Group Decision Support: Issues and Alternatives in Knowledge Elicitation. European Journal of Operational Research, 59(1), $28-41$. https://doi.org/10.1016/0377-2217(92)90005-T

Verma, D., \& Sinha, K.K. (2002). Toward a Theory of Project Interdependencies in high Tech R\&D Environments. Journal of Operations Management, 20, 451-468. https://doi.org/10.1016/S0272-6963(02)00024-4 
Warglien, M. (2010). Seeing, Thinking and Deciding: Some Research Questions on Strategy and Vision, In Warglien, M., \& Jacobides, M.G. (Eds.)., The Power of Representations: From Visualization, Maps and Categories to Dynamic Tools. Academy of Management Meeting, Montreal.

Wheeler, D. (2013). Contributing Factors to Optimal Project Portfolio Selection. Thesis. Queensland University of Technology.

Williams, T. (2007). Post-Project Reviews to Gain Effective Lessons Learned. Newtown Square, PA: Project Management Institute.

Yu, S., Wang, J., \& Guo, N. (2008). The Application of Project Portfolio Management in the Government Investment Projects. International Seminar on Business and Information Management, 513-516.

https://doi.org/10.1109/ISBIM.2008.207

Zhao, W. (2011). Two-Sided Markets Model and Its Applications. Dissertation. Stanford University.

Journal of Industrial Engineering and Management, 2018 (www.jiem.org)

\section{@(1) $\Theta$}

Article's contents are provided on an Attribution-Non Commercial 4.0 Creative commons International License. Readers are allowed to copy, distribute and communicate article's contents, provided the author's and Journal of Industrial Engineering and Management's names are included. It must not be used for commercial purposes. To see the complete license contents, please visit https://creativecommons.org/licenses/by-nc/4.0/. 